\title{
HUBUNGAN KENAIKAN BERAT BADAN DENGAN LAMA PEMAKAIAN KB SUNTIK 3 BULAN PADA PUS DI DESA JATIJAJAR RW 01 KECAMATAN BERGAS KABUPATEN SEMARANG
}

\author{
Widyah Setiyowati $^{1)}$, Titik Kurniawati ${ }^{2)}$. Atika Rizky Suryani ${ }^{3)}$ \\ ${ }^{1}$ Prodi D III Kebidanan STIKes Guna Bangsa \\ ${ }^{2}$ Prodi S1 Kebidanan STIKes Guna Bangsa \\ ${ }^{3}$ Prodi D III Kebidanan Universitas STEKOM \\ Email: Widyahsetiyowati@gmail.com
}

\begin{abstract}
ABSTRAK
Menurut UU No.10 tahun 1992 Keluarga berencana adalah upaya peningkatan kepedulian dan peran serta masyarakat melalui pendewasaan usia perkawinan, pengaturan kelahiran, pembinaan ketabahan keluarga, peningkatan kesejahteraan keluarga untuk mewujudkan keluarga kecil, bahagia, dan sejahtera. Pengguna KB di Desa Jatijajar RW 01 Kecamatan Bergas Kabupaten Semarang sebanyak 148 jiwa terdiri atas IUD 8 jiwa, MOP 0 jiwa, MOW 2 jiwa, implant 1 jiwa, suntik 1 bulan 38 jiwa, suntik 3 bulan 89 jiwa, pil 4 jiwa, kondom 5 jiwa. Tujuan penelitian untuk mengetahui hubungan lama pemakaian KB suntik 3 bulan dengan kejadian kenaikan berat badan pada akseptor KB. Jenis penelitian ini adalah survey dengan menggunakan rancangan penelitian korelasi. Populasi dalam penelitian ini sebanyak 89 ibu yang mengunakan KB suntik 3 bulan. Jumlah sampel 47 responden dengan tekhnik simple random sampling. Pengujian hipotesisnya menggunakan uji chi square. Hasil penelitian ini menunjukkan bahwa sebagian besar responden mengalami kenaikan berat badan 35 $(74,5 \%)$ dan sebagaian besar responden telah memakai KB suntik 3 bulan $\geq 1$ tahun yaitu sebanyak 38n (80,9\%). Berdasarkan hasil uji statistik menggunakan perhitungan Chi Square dengan $\alpha=0,05$ diperoleh nilai $\rho$ sebesar 0,014 , maka ada hubungan lama penggunaan dengan kenaikan berat badan. Saran yang diberikan kepada masyarakat khususnya ibu hendaknya aktif mencari informasi kepada tenaga kesehatan mengenai alat kontrasepsi yang akan dipakai agar dapat mengetahui efek samping kontrasepsi dan cara
\end{abstract}

Kata Kunci: KB, kenaikan BB, lama pemakaian KB

\section{ABSTRACT}

According to Law No. 10 of 1992, family planning is an effort to increase awareness and community participation through maturing the age of marriage, birth control, fostering family resilience, increasing family welfare to create a small, happy and prosperous family. Family planning users in Jatijajar Village, RW 01, Bergas District, Semarang Regency, as many as 148 people consisting of 8 people for IUD, 0 people for MOP, 2 people for $M O W, 1$ implant, 38 people for 1 month injection, 89 people for 3 months injection, 4 pills, 5 condom soul. The purpose of the study was to determine the relationship between duration of use of injectable contraceptives for 3 months with the incidence of weight gain in family planning acceptors. This type of research is a survey using a correlation research design. The population in this study were 89 mothers who used 3-month injections. The number of samples is 47 respondents with simple random sampling technique. Testing the hypothesis using the chi square test. The results of this study indicate that most of the respondents experienced weight gain of 35 (74.5\%) and most of the respondents had used injectable contraception for 3 months 1 year, namely 38n (80.9\%). Based on the results of statistical tests using Chi Square calculations with $=0.05$, the value of is 0.014, so there is a relationship between length of use and weight gain. Suggestions given to the community, especially mothers, should actively seek information from health workers regarding contraceptives to be used in order to know the side effects of contraception and how to overcome them.

Keywords: $K B$, increase in weight, length of use of $K B$

\section{PENDAHULUAN}

Indonesia merupakan Negara dengan jumlah penduduk terbesar keempat setelah
RRC, India dan Amerika Serikat. Jumlah penduduk Indonesia terus meningkat, hingga tahun 2016 mencapai 258,7 juta jiwa. Laju 
pertumbuhan penduduk Indonesia tahun 2016 sebesar $1,38 \%$ yag sudah menurun dari tahun sebelumnya yaitu tahun 2014 sebesar 1,49\%. Hal ini belum sesuai target Rancangan strategis Badan Kependudukan dan Keluarga Berencana yaitu, 1,19 ditahun 2019 (BPS, 2016 dan Renstra BKKBN tahun 2015-2019).

Saat ini diperkirakan terdapat sekitar 3,5 juta wanita usia subur (WUS) di Indonesia yang ingin menunda, menjarangkan dan membatasi kelahiran untuk masa dua tahun berikutnya, namun tidak menggunakan metode kontrasepsi apapun. Berdasarkan SDKI 2007, unnet need mencapai $9,1 \%$ dari sejumlah WUS, dan alasan WUS tidak menggunakan kontrasepsi sebagian besar adalah karena efek samping dari metode kontrasepsi. Efek samping dari metode kontrasepsi juga merupakan faktor yang menyebabkan akseptor mengalami drop-out ari $\mathrm{KB}$ yang digunakan (Witjaksono, J. 2012)

Undang-undang Nomor 52 tahun 2009 yang menjelaskan tentang Perkembangan Kependudukan dan Pembangunan keluarga menyebutkan bahwa Keluarga Berencana (KB) adalah upaya untuk mengatur kelahiran anak, jarak, kemudian usia ideal melahirkan, mengatur kehamilan dengan melalui promosi, perlindungan dan bantuan sesuai dengan hak reproduksi untuk mewujudkan keluarga yang berkualitas (BKKBN,2011).

Terdapat beberapa jenis kontrasepsi yang terbagi dalam dua kategori, yaitu metode kontrasepsi modern dan tradiisional. Metode kontrasepsi modern meliputi sterilisasi, pil KB, suntik KB, implan, kondom, kontrasepsi darurat, sedangkan metode tradisional terdiri dari pantang berkala (kalender), metode amenorrhea laktasi (MAL) dan senggama terputus. Pil $\mathrm{KB}$ dan suntik $\mathrm{KB}$ merupakan metode kontrasepsi yang paling dikenal oleh masyarakat presentase masing-masing 97\% dibanding 98\%. Diantara metode KB modern yang dipakai, suntik KB merupakan alat kontrasepsi terbanyak yang digunakan oleh wanita yang sudah menikah (32\%). Diikuti pil KB $(13,6 \%)$. Dan IUD (3,9\%)(Badan pusat statistik, 2012).

Dari survai awal yang dilakukan terhadap akseptor KB suntik 3 bulan dari 10 akseptor $70 \%$ diantaranya mengalami gangguan menstruasi, peningkatan berat badan, sakit kepala dan lamanya kembali ke masa fertilitas. Berdasarkan penelitian yang dilakukan di Desa duriwetan kecamataan Maduran Lamongan tahun 2013 dapat dijelaskan hampir 42,5\% tidak mengalami kecemasan (Ningsih,A.F, 2012).

Kontrasepsi suntik memiliki kelebihan dan kekurangan. Kekurangan dari kontrasepsi suntik adalah tergantngaanya pola haid diantaranya amenorhea, menorogia dan muncul bercak (spooting), terlambatnya kembali kesuburan setelah penghentian pemakaian dan efek samping tersering adalah peningkatan berat badan( Saefudin, 2006).

Umumnya penambahan berat badan tidak terlalu besar, bervariasi antara kurang dari $1 \mathrm{~kg}$ sampai $5 \mathrm{~kg}$ dalam tahun pertama. Tampaknya terjadi karena bertambahnya lemak tubuh, dan bukan karena retensi cairan tubuh. Penyebab pertambahan berat badan tidak jelas. Hipotesa para ahli DMPA merangsang pusat pengendalian nafsu makan di hypotalamus, yang menyebabkan akseptor makan lebih banyak dari biasanya. (Hartanto, 2004)

Berdasarkan data dari BKKBN Provinsi Jawa Tengah tahun 2017, jumlah peserta KB aktif sebanyak 1,5 juta $(28,85 \%)$ pasangan usia subur dengan memperlihatkan proporsi pengguna alat kontrasepsi terbanyak adalah pengguna KB suntik 69.997 akseptor. KB pil 9.915 akseptor. (BKKBN, 2019)

Berdasarkan data dari data sensus Kabupaten Semarang tahun 2017 jumlah pasangan Usia subur sebanyak 199.103 jiwa, 2018 sebanyak 198.1432 jiwa,

Berdasarkan data sensus penduduk tahun 2017 kecamatan Bergas jumlah pasangan usia subur sebanyak 13.860 jiwa, tahun 2018 sebanyak 15.711 jiwa, peserta KB 11351 jiwa, pasangan Usia subur sebanyak 15711 jiwa, IUD 1437 jiwa, MOP 95 jiwa, MOW 436 jiwa, implan 1740 jiwa, suntik 6498 jiwa, pil 1505 jiwa, kondom 24 jiwa (Data sensus, 2018)

Pengguna KB di Desa Jatijajar RW 01

Kecamatan Bergas Kabupaten Semarang jumlah peserta KB sebanyak 148 jiwa, IUD 8 jiwa, MOP 0 jiwa, MOW 2 jiwa, implant 1 jiwa, suntik 1 bulan 38 jiwa, suntik 3 bulan 89 jiwa, pilm4 jiwa, kondom 5 jiwa (Data kader Desa Jatijajar RW 01, 2020)

Tujuan penelitian ini adalah untuk mengetahui hubungan lama pemakaian $\mathrm{KB}$ suntik 3 bulan dengan kejadian kenaikan berat badan pada PUS (Pasangan Usia Subur) di 
Desa Jatijajar RW 01 Kecamatan Bergas Kabupaten Semarang.

\section{METODE}

Penelitian ini menggunakan rancangan cross sectional, menurut sifat dasar, penelitian ini termasuk jenis penelitian "analitik korelasional" yaitu dengan menghubungan variabel independen (lama pemakaian suntik 3 bulan ) dan variabel dependen (kenaikan berat badan) (Hidayat, 2007)

Populasi akseptor KB suntik 3 bulan di Desa Jatijajar RW01 Kecamatan Bergas Kabupaten Semarang berjumlah 89 jiwa. Dalam pengambilan sampel menggunakan tekhnik simple random sampling dengan jumlah sampel 47 responden.
Jenis data pada peneltian ini terdiri dari data primer dan sekunder. Data primer didapatkan dengan menggunakan kuesioner keoada akseptor KB suntik 3 bulan.

Analisa data terdiri atas analisa univariat untuk mendiskripsikan karakteristik tiap variable dan analisa bivariate menggunakan rumus Chi kuadrat

Hipotesa dalam penelitian ini jika nilai $p \leq 0,05$ maka ada hubungan bermakna antara variable kenaikan berat badan dengan lama pemakaian KB suntik 3 bulan

\section{HASIL}

A. Lama Pemakaian KB Suntik

Tabel 1

Distribusi Frekuensi Lama pemakaian KB Suntik 3 bulan

\begin{tabular}{ccc}
\hline Lama Pemakaian & Frekuensi & \% \\
\hline$\geq \mathbf{1}$ tahun & 38 & 80,9 \\
\hline $\mathbf{1}$ tahun & 9 & 19,1 \\
\hline Total & 47 & 100 \\
\hline Berdasarkan table diatas didapatkan hasil & KB suntik 3 bulan $\geq 1$ tahun yaitu sebanyak \\
bahwa sebagaian besar ibu telah memakai & 38 (80,9\%) responden. \\
& B. Peningkatan BB &
\end{tabular}

Tabel 2

Distribusi Frekuensi peningkatan BB

\begin{tabular}{ccc}
\hline Peningkatan BB & Frekuensi & \% \\
\hline Tidak naik & 12 & 25,5 \\
\hline Naik & 35 & 74,5 \\
\hline Total & 47 & 100 \\
\hline
\end{tabular}

Berdasarkan penelitian yang dilakukan sebagaimana tersaji dalam table diatas, sebagaian besar ibu mengalami peningkatan berat badan yaitu naik

C. Hubungan Lama Pemakaian KB sutik dan Kenaikan BB

Tabel 3

Tabulasi silang lama pemakaian KB Suntik 3 bulan dengan peningkatan BB

$\begin{array}{lll}\text { Lama Penggunaan } & \text { Teningkatan BB } \\ \text { KB suntik } 3 \text { bulan } & \text { Total }\end{array}$

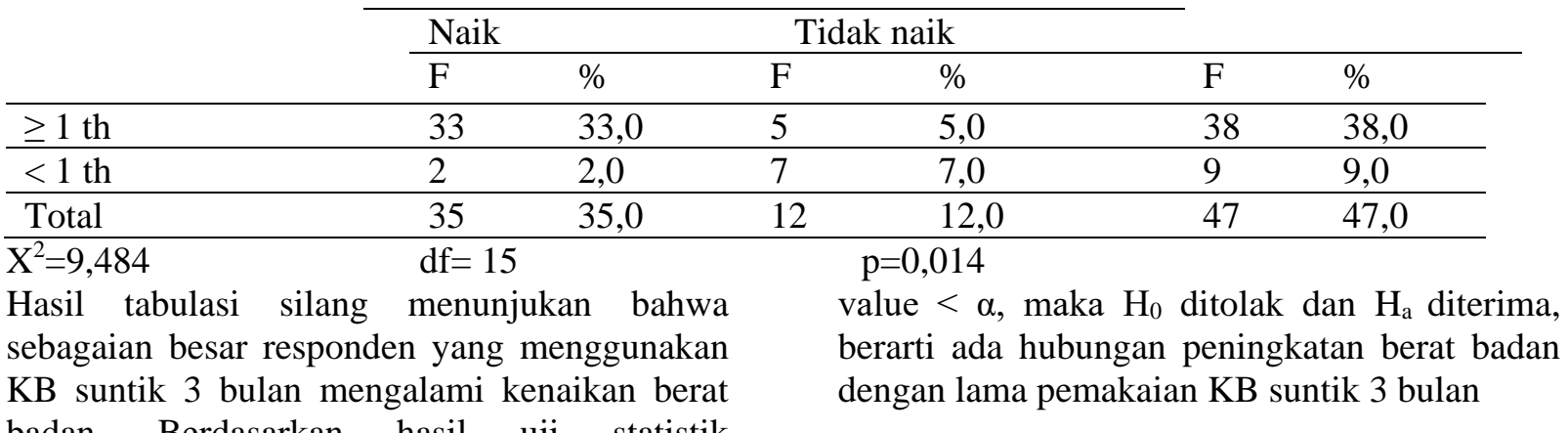

badan. Berdasarkan hasil uji statistik menggunakan perhitungan Chi Square dengan $\alpha$ $=0,05$ diperoleh nilai $\rho$ sebesar 0,014 , dimana $\rho$ 


\section{PEMBAHASAN}

A. Lama Pemakaian KB Suntik

Berdasarkan penelitian yang dilakukan mengenai hubungan lama pemakaian KB Suntik 3 bulan dengan peningkatan berat badan pada PUS ( Pasangan Usia Subur) di Desa Jatijajar RW 01 Kecamatan Bergas Kabupaten Semarang, diperoleh hasil bahwa sebagaian besar ibu memakai $\mathrm{KB}$ suntik 3 bulan $\geq 1$ tahun sebanyak 38 $(80,9 \%)$ responden. Menurut KBBI ( Kamus Besar Bahasa Indonesia) lama artinya panjang antaranya( tentang Waktu), Pemakaian artinya proses, cara, perbuatan memakai, penggunaan, jadi lama pemakaian adalah panjangnya atau lamanya penggunaan. Pemakaian KB suntik 3 bulan dalam jangka panjang dapat memungkinkan terjadinya osteoporosis, selain terjadi osteoporosis, pemakaian jangka panjang juga dapat mengakibatkan amenore (Everett, 2008)

B. Kenaikan BB

Berdasarkan penelitian yang dilakukan mengenai hubungan lama pemakaian $\mathrm{KB}$ suntik 3 bulan dengan peningkatan berat badan pada PUS (Pasangan Usia Subur) di Desa Jatijajar RW 01 Kecamatan Bergas Kabupaten Semarang, diperoleh hasil bahwa sebagian ibu mengalami kenaikan Berat badan sebesar 35 (74,5\%) responden. Menurut teori Soetjiningsih peningkatan berat badan adalah hasil peningkatan/penurunan semua jaringan yang ada pada tubuh, antara lain tulang, otot, lemak, cairan tubuh dan lain-lain. Faktor yang mempengaruhi peningkatan berat badan akseptor KB suntik adalah adanya hormone progesterone yang kuat sehingga merangsang hormone nafsu makan yang lebih banyak dari biasanya tubuh akan kelebihan zat-zat gizi oleh hormone progesterone dirubah menjadi lemak dan disimpan dibawah kulit. Perubahan berat badan ini akibat adanya penumpukan lemak yang berlebih hasil sintesa dari karbohidrat menjadi lemak (Mansjoer, 2003).

C. Hubungan Lama Pemakaian dan Kenaikan $\mathrm{BB}$

Berdasarkan hasil penelitian, didapatkan adanya hubungan lama pemakaian KB suntik 3 bulan dengan kejadian peningkatan berat badan pada PUS (Pasangan Usia
Subur) di Desa Jatijajar RW 01 Kecamatan Bergas Kabupaten Semarang, dengan $p$ value 0,014 dimana ibu yang menggunakan KB suntik 3 bulan lebih dari 1 tahun mengalami kenaikan berat badan. Hasil penelitian ini sesuai dengan teori bahwa salah satu efek samping dari metode suntikan adalah adanya penambahan berat badan. Umunya pertambahan berat badan bervariasi antara kurang dari $1 \mathrm{~kg}$ sampai 5 $\mathrm{kg}$ dalam pemakaian tahun pertama. Hipotesa para ahli DMPA merangsang pusat pengendalian nafsu makan lebih banyak dari biasanya (Hartanto, 2013). Menurut Saiffudin (2006), KB DMPA mempunyai resiko terjadinya kenaikan berat badan meningkat. Resiko kenaikan berat badan kemungkinan disebabkan karena hormone progesterone mempermudah perubahan karbohidrat dan gula menjadi lemak, sehingga lemak dibawah kulit bertambah, selain itu hormone progesterone juga menyebabkan nafsu makan bertambah dan menurunkan aktivitas fisik, akibatnya pemakaian suntikan ini dapat menyebabkan berat badan bertambah.

\section{SIMPULAN DAN SARAN Simpulan}

1. Sebagian besar ibu yang menggunakan KB suntik 3 bulan $\geq 1$ tahun sebanyak 35 $(74,5 \%)$ responden.

2. Sebagaian besar ibu memakai KB suntik 3 bulan mengalami kenaikan sebanyak $35 \mathrm{n}$ $(80,9 \%)$ responden.

3. Ada hubungan antara lama pemakaian $\mathrm{Kb}$ suntik 3 bulan dengan kejadian kenaikan berat badan. Hal ini dibuktikan dengan nilai $p=0,014$, dimana $\rho$ value $<\alpha$, maka $\mathrm{H}_{0}$ ditolak dan $\mathrm{H}_{\mathrm{a}}$ diterima.

\section{Saran}

1. Pemerintah (PLKB) Kabupaten Semarang

Pemerintah diharapkan meningkatkan akses, sarana dan prasarana serta meningkatkan pelayanan masyarakat dalam pelayanan KB.

2. Tenaga kesehatan

Tenaga kesehatan diharapkan dapat meningkatkan pengetahuan tenaga kesehatan akan adanya efek samping yang banyak dialami oleh akseptor KB 
suntik dan dapat memberikan informasi kepada masyarakat melalui KIE.

3. Peneliti

Peneliti diharapkan dapat termotifasi untuk melakukan penelitian lebih lanjut dan dapat menambah pengetahuan dan pengalaman dalam penelitian KB.

4. Institusi Pendidikan

Institusi diharapkan memperbanyak referensi perpustakaan mengenai alat kontraspesi KB untuk menambah wawasan pengetahuan bagi mahasiswa.

5. Masyarakat

Ibu hendaknya aktif mencari informasi atau aktif bertanya kepada tenaga kesehatan mengenai alat kontrasepsi yang akan dipakai agar dapat mengetahui efek samping dan cara mengatasinya.

\section{DAFTAR PUSTAKA}

Arikunto. 2006. Prosedur Penelitian Suatu Pendekatan Praktek. Jakarta: Rineka Cipta .2010. Prosedur Penelitian Suatu Kedekatan praktek. Jakarta: Rineka Cipta.

Anggraini, Yety dan Martini. 2011. Buku Ajar Pelayanan Keluarga Berencana .Yogyakarta: Pustaka

Rihama Barasi,M. 2007. Ilmu Gizi. Jakarta:Erlangga.

Everett. 2005. Buku Saku kontrasepsi dan Kesehatabn Seksual Reproduksi. Jakarta: EGC

2008. Buku Saku Kontrasepsi Dan

Kesehatan

Seksual

Reproduksi.Jakarta:EGC

Glasier. 2005. Keluarga berencana dan kesehatan reproduksi.Jakarta:EGC

Hidayat, Alimul. 2007. Metode penelitian kebidanan teknik Analisa Data. Jakarta:Salemba Medika.

.2010. Metode Penelitian Kebidanan

Teknik Analisa Data. Jakarta; Salemba Medika

Handayani, S. 2010. Buku Ajar Pelayanan Keluarga Berencana. Yogyakarta: Pustaka Rihana

Hartanto, H. 2003. Keluarga Berencana Dan Kontrasepsi.Jakarta: Pustaka Sinar Harapan
.2004. Keluarga Berencana Dan Kontrasepsi. Jakarta: Pustaka Sinar Harapan.

Kurnia. Titik dan Dr Lucky. 2013. Buku Ajar Kependudukan Dan Pelayanan KB. Jakarta:EGC

Notoatmojo, S. 2010. Metodologi Penelitian Kesehatan. Jakarta: Rineka Cipta

2012. Meotodologi Penelitian Kesehatan. Jakarta: Rineka Cipta

Saifuddin, 2006. Buku Panduan Praktis Pelayanan Kontrasepsi. Jakarta:YBP-SP

Pelayanan 